\title{
Association of Platelet Count and Mean Platelet Volume with Overall Survival in Patients with Cirrhosis and Unresectable Hepatocellular Carcinoma
}

\author{
Bernhard Scheinera, b, e Martha Kirstein ${ }^{c}$ Sabine Popp ${ }^{a}$ \\ Florian Hucke ${ }^{a}$, d d Simona Bota ${ }^{a, b}$, Nataliya Rohr-Udilova ${ }^{a}$ b \\ Thomas Reiberger ${ }^{a, e} \quad$ Christian Müller ${ }^{a, b} \quad$ Michael Trauner ${ }^{a}$ \\ Markus Peck-Radosavljevic a, b, d, e Arndt Vogel ${ }^{c}$ Wolfgang Sieghart ${ }^{a, b}$ \\ Matthias Pinter ${ }^{a}$ b \\ ${ }^{a}$ Division of Gastroenterology and Hepatology, Department of Internal Medicine III, Medical \\ University of Vienna, Vienna, Austria; ${ }^{b}$ Liver Cancer (HCC) Study Group Vienna, Medical \\ University of Vienna, Vienna, Austria; ' ${ }^{\circ}$ Department of Gastroenterology, Hepatology \\ and Endocrinology, Hannover Medical School, Hannover, Germany; d Department of \\ Gastroenterology and Hepatology, Endocrinology, Rheumatology and Nephrology, \\ Klinikum Klagenfurt am Wörthersee, Klagenfurt, Austria; 'Vienna Hepatic Hemodynamic \\ Laboratory, Medical University of Vienna, Vienna, Austria
}

\section{Keywords}

Thrombocytopenia $\cdot$ Mean platelet volume $\cdot$ Hepatocellular carcinoma $\cdot$ Cirrhosis $\cdot$ Survival

\begin{abstract}
Background: Platelets have been reported to influence tumor biology and may promote metastasis. Traditionally, thrombocytopenia, a hallmark of cirrhosis, was associated with hepatocellular carcinoma (HCC) development. However, the impact of platelet count on outcome in patients with established HCC is not well studied. Methods: Outcomes of patients with cirrhosis diagnosed with HCC between 1995 and 2013 (derivation cohort) and 2000-2016 (validation cohort) who were not eligible for surgical treatment and did not receive antiplatelet therapy were retrospectively studied. Thrombocytopenia was defined as platelet count $<150$ $\mathrm{g} / \mathrm{L}$. High mean platelet volume (MPV) was defined as $\geq$ median value of the respective cohort (derivation cohort: $\geq 11 \mathrm{fL}$; validation cohort: $\geq 10.6 \mathrm{fL}$ ). Results: Among 626 patients with unresectable HCC, thrombocytopenia was present in 378 (60.4\%) and was associated with favorable baseline tumor characteristics: lower diameter of the largest nodule $(5.6 \pm 3.2$ vs. $7.6 \pm$
\end{abstract}


$4.2 \mathrm{~cm}$ ), less extrahepatic spread (9.5 vs. $20.2 \%$, both $p<0.001)$, less macrovascular invasion (21.2 vs. $31.0 \%, p=0.005)$, and lower BCLC stages (63.0 vs. $73.4 \%$ BCLC C/D; $p=0.007$ ) as compared to patients with normal platelet count. On univariate analysis, thrombocytopenia and larger MPV were associated with longer overall survival (OS) (thrombocytopenia: median OS [95\% Cl], 11.5 [9.3-13.8] vs. 5.5 [3.8-7.1] months; $p=0.001 ; \mathrm{MPV} \geq 11 \mathrm{fL}: 11.7$ [9.1-14.2] vs. 6.0 [4.4-7.6] months; $p<0.001)$. In multivariate analysis, the combined variable of thrombocytopenia and larger MPV was independently associated with longer OS (HR [95\% Cl], 0.80 [0.650.98 ] $p=0.029$ ). These results were confirmed in an independent external validation cohort of 525 patients with cirrhosis and HCC. Again, patients with thrombocytopenia and high MPV had significantly longer OS (15.3 [11.7-18.9] vs. 9.3 [7.4-11.2] months; $p<0.001)$. Conclusions: Thrombocytopenia and higher MPV are associated with better outcome in patients with advanced HCC. These findings may prompt further clinical research on additive antiplatelet therapy in the prevention and management of HCC.

(C) 2018 S. Karger AG, Basel

\section{Introduction}

Hepatocellular carcinoma (HCC) usually develops in patients with liver cirrhosis $[1,2]$. Prognosis of HCC is not only associated with tumor characteristics but also with the degree of underlying liver disease [3]. Overall, HCC represents the second leading cause of cancerrelated death in men and the sixth leading cause of cancer-related death in women, respectively [4]. It is estimated that only $40 \%$ of HCCs are diagnosed in early stages [5], when patients are amenable to curative treatments, such as surgical resection, local ablation, or liver transplantation $[1,6]$. In advanced stages, only palliative treatments can be provided, and overall survival (OS) is limited but highly variable depending on tumor characteristics [7]. Biochemical markers predicting the individual patient's survival are currently being studied in the setting of HCC not eligible for surgery [8, 9].

Evidence from several sources has recently suggested that thrombocytes have multiple functions other than thrombosis and hemostasis and that they play an important role in inflammation, immunity, malignancy, and organ regeneration $[10,11]$. In vitro studies showed that tumor cells can aggregate thrombocytes [12] and may "use" platelet aggregates as "shield" for protection from immune-cell-mediated clearance [13]. Platelets may also promote formation of metastasis [14]. In line with this, recent clinical data showed a correlation of elevated thrombocyte counts and worse prognosis in several cancer entities [15-18] as well as an increased risk of distant metastasis $[19,20]$ and recurrence of disease after liver transplantation [21] in patients with HCC. Prophylactic treatment with daily acetylsalicylic acid significantly reduced the risk of adenocarcinoma development [22]. Therefore, medication inhibiting platelet function may be helpful as an additive treatment for several cancer entities [23].

In contrast, thrombocytopenia, which is a hallmark of advanced liver disease and portal hypertension, has been associated with HCC development in cirrhotic patients with hepatitis C infection [24, 25]. However, it is unclear if thrombocytopenia per se favors HCC or is just a marker of more severe liver disease [24]. Furthermore, a lower mean platelet volume (MPV) was found to be an independent predictor of a reduced OS in patients with various cancer entities (excluding HCC) [26-28] with an especially pronounced effect in patients with localized solid tumors [29]. However, currently there is limited knowledge on the impact of platelet indices on tumor biology, outcomes, and survival in patients with established HCC [30]. 


\section{Liver Cancer}

\begin{tabular}{l|l}
\hline Liver Cancer 2019;8:203-217 \\
\hline DOI: 10.1159/000489833 & $\begin{array}{l}\text { @ 2018 S. Karger AG, Basel } \\
\text { www.karger.com/lic }\end{array}$ \\
\hline
\end{tabular}

Scheiner et al.: Platelets and HCC

Fig. 1. Patient flow chart. HCC, he-

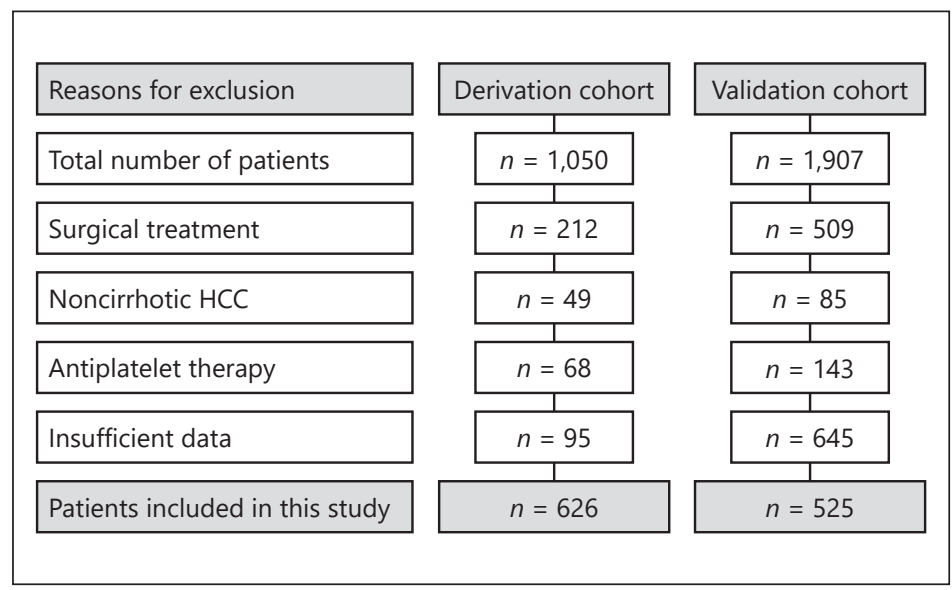
patocellular carcinoma.

The aim of this study was to evaluate (a) the prognostic impact of platelet counts and indices in cirrhotic patients with HCC, and (b) the clinical impact of platelet indices within different BCLC stages in order to reveal a patient population potentially profiting most from additive antiplatelet therapy.

\section{Materials and Methods}

Study Design

Patients diagnosed with HCC between 1995 and 2013 at the Division of Gastroenterology, Medical University of Vienna, were retrospectively included (derivation cohort). Furthermore, results were confirmed in an independent cohort of patients with cirrhosis and HCC diagnosed between 2000 and 2016 at Hannover Medical School (validation cohort). Diagnosis of liver cirrhosis was either established by liver histology or a combination of typical radiographic, clinical, and laboratory findings. HCC was diagnosed either by histology or dynamic imaging (computed tomography/magnetic resonance imaging scans) according to the European Association for the Study of the Liver (EASL) guidelines [1]. The retrospective data analysis was approved by the local ethics committee of the Medical University of Vienna.

\section{Patients and Definitions}

Patients treated with liver surgery or on antiplatelet therapy, noncirrhotic patients, and those with insufficient records were excluded from the study. Patient characteristics and information on important lifestyle factors (e.g., alcohol consumption), laboratory parameters including platelet counts and indices, tumor characteristics, and general performance status (ECOG-PS) were collected from the clinical documentation system at the time of diagnosis and until the death of the patient or last contact. According to the primary study aim, patients were divided into four groups according to the presence of thrombocytopenia (platelet count $<150 \mathrm{~g} / \mathrm{L}$, lower limit of normal) and MPV (MPV $</ \geq$ median value of the respective cohort; derivation cohort: $\geq 11 \mathrm{fL}$, validation cohort: $\geq 10.6 \mathrm{fL}$ ). Liver function at baseline was assessed by MELD and Child-Pugh score [31].

\section{Mean Platelet Volume}

MPV describes the size of thrombocytes and reflects thrombocyte activity as shown by an association with platelet aggregation and thromboxane B2 release [29]. This parameter is measured routinely in our institution by using a Sysmex XE-2100 hematology analyzer.

\section{Statistics}

Statistical analyses were performed using IBM SPSS Statistics 23 (SPSS Inc., Armonk, NY, USA) and GraphPad Prism 6 (GraphPad Software, La Jolla, CA, USA). Continuous variables are reported as mean \pm standard deviation or median (range), and categorical variables are shown as numbers $(n)$ and proportions 


\section{Liver Cancer}

\begin{tabular}{l|l}
\hline Liver Cancer 2019;8:203-217 \\
\hline DOI: 10.1159/000489833 & $\begin{array}{l}\text { @ 2018 S. Karger AG, Basel } \\
\text { www.karger.com/lic }\end{array}$ \\
\hline
\end{tabular}

Scheiner et al.: Platelets and HCC

Table 1. Baseline demographics and tumor characteristics

\begin{tabular}{|c|c|c|}
\hline & Derivation cohort & Validation cohort \\
\hline Patients & $626(100 \%)$ & $525(100 \%)$ \\
\hline Age, years & $64 \pm 9.1(32-87)$ & $64 \pm 10(24-87)$ \\
\hline \multicolumn{3}{|l|}{ Sex } \\
\hline Male & $506(81 \%)$ & $389(74 \%)$ \\
\hline Female & $120(19 \%)$ & $136(26 \%)$ \\
\hline \multicolumn{3}{|l|}{ Diabetes } \\
\hline NIDDM & $138(22 \%)$ & $203(39 \%)$ \\
\hline IDDM & $69(11 \%)$ & \\
\hline None & $419(67 \%)$ & $322(61 \%)$ \\
\hline BMI & $27 \pm 5.0$ & $27 \pm 4.8$ \\
\hline \multicolumn{3}{|l|}{ Etiology } \\
\hline Alcohol & $293(47 \%)$ & $179(34 \%)$ \\
\hline $\mathrm{HCV}$ & $200(32 \%)$ & $149(28 \%)$ \\
\hline $\mathrm{HBV}$ & $42(7 \%)$ & 73 (14\%) \\
\hline NASH & $14(2 \%)$ & $63(12 \%)$ \\
\hline Other & 77 (12\%) & $61(12 \%)$ \\
\hline \multicolumn{3}{|l|}{ Child-Pugh } \\
\hline A & $234(38 \%)$ & $199(37 \%)$ \\
\hline B & $227(36 \%)$ & $250(48 \%)$ \\
\hline $\mathrm{C}$ & $165(26 \%)$ & $76(15 \%)$ \\
\hline \multicolumn{3}{|l|}{ ECOG PS } \\
\hline 0 & $288(46 \%)$ & $256(49 \%)$ \\
\hline$\geq 1$ & $338(54 \%)$ & $265(51 \%)$ \\
\hline \multicolumn{3}{|l|}{ Largest tumor } \\
\hline$\leq 5 \mathrm{~cm}$ & $286(46 \%)$ & $261(50 \%)$ \\
\hline$>5 \mathrm{~cm}$ & $340(54 \%)$ & $205(39 \%)$ \\
\hline \multicolumn{3}{|c|}{ Macrovascular invasion } \\
\hline No & $469(75 \%)$ & $375(71 \%)$ \\
\hline Yes & $157(25 \%)$ & $133(25 \%)$ \\
\hline \multicolumn{3}{|c|}{ Extrahepatic metastases } \\
\hline No & $540(86 \%)$ & $481(92 \%)$ \\
\hline Yes & $86(14 \%)$ & $36(7 \%)$ \\
\hline \multicolumn{3}{|l|}{ BCLC stage } \\
\hline A & $72(12 \%)$ & $76(14 \%)$ \\
\hline B & $134(21 \%)$ & $126(24 \%)$ \\
\hline $\mathrm{C}$ & $252(40 \%)$ & $243(47 \%)$ \\
\hline D & $168(27 \%)$ & $80(15 \%)$ \\
\hline \multicolumn{3}{|l|}{ First-line therapy } \\
\hline PEI/RFA /MWA & $123(20 \%)$ & $88(17 \%)$ \\
\hline $\mathrm{TA}(\mathrm{C}) \mathrm{E}$ & $165(26 \%)$ & $187(36 \%)$ \\
\hline Sorafenib & $49(8 \%)$ & $3(-)$ \\
\hline $\mathrm{BSC}$ & $151(24 \%)$ & $181(34 \%)$ \\
\hline Other & $138(22 \%)$ & $66(13 \%)$ \\
\hline Thrombocytes, g/L & $150 \pm 86$ & $144 \pm 76$ \\
\hline MPV, fL & $11 \pm 1.3$ & $10.5 \pm 1.5$ \\
\hline
\end{tabular}

Data are presented as mean \pm SD (range) or as stated. NIDDM, non-insulin dependent diabetes mellitus; IDDM, insulin-dependent diabetes mellitus; BMI, body mass index; HCV, hepatitis C virus; HBV, hepatitis B virus; NASH, non-alcoholic steatohepatitis; ECOG PS, Eastern Cooperative Oncology Group performance status; BCLC, Barcelona Clinic Liver Cancer; PEI, percutaneous ethanol injection; RFA, radiofrequency ablation; MWA, microwave ablation; TA(C)E, transarterial (chemo)embolization; BSC, best supportive care; MPV, mean platelet volume. 


\section{Liver Cancer}

\begin{tabular}{l|l}
\hline Liver Cancer 2019;8:203-217 \\
\hline DOI: 10.1159/000489833 & $\begin{array}{l}\text { @) 2018 S. Karger AG, Basel } \\
\text { www.karger.com/lic }\end{array}$ \\
\hline
\end{tabular}

Scheiner et al.: Platelets and HCC

(\%) of patients. Comparisons of proportions and of continuous variables were performed by the $\chi^{2}$ test and Student $t$ test, respectively. OS was defined as the time from date of diagnosis (biopsy if available or diagnostic imaging) until date of death or last contact. Survival curves were calculated by the Kaplan-Meier method. Univariate analyses were performed by the log rank test. Multivariate Cox regression analysis was used for evaluation of prognostic parameters associated with mortality. A two-sided $p$ value $\leq 0.05$ was considered statistically significant.

\section{Results}

Patients

Among 1,050 patients diagnosed with HCC at the Medical University of Vienna, 212 patients who underwent surgical resection, 49 without cirrhosis, and 68 on antiplatelet therapy were excluded from the study. Additional 95 patients with insufficient records had to be excluded. A final cohort of 626 patients with HCC was included in the derivation cohort. A total of 525 patients were included in the validation cohort (Fig. 1).

\section{Patient Characteristics}

Derivation Cohort

The majority of patients were male (81\%) with a mean age of $64 \pm 9.1$ years. Alcohol abuse (47\%) was the main etiology of liver cirrhosis, followed by viral hepatitis C (32\%) and B (7\%). While $38 \%$ of patients presented with Child-Pugh stage A, the remaining $62 \%$ had advanced liver disease (Child-Pugh B/C), which was also reflected by an overall MELD of 13 \pm 5.8 points. Most patients had intermediate-advanced HCC (BCLC stage B: $21 \%$, C: $40 \%$ ). Thrombocytopenia was present in 378 (60.4\%) (Table 1).

Validation Cohort

Detailed patient characteristics are shown in Table 1. In summary, the majority of patients were male $(74 \%)$ with a mean age of $64 \pm 10$ years. Three out of 4 patients had intermediateadvanced HCC (BCLC stage B: $24 \%$, C: 47\%) .

Association of Platelet Count and MPV with Characteristics of Tumor and Liver Disease

Notably, patients with thrombocytopenia had a significantly smaller diameter of the largest tumor at diagnosis when compared to patients with a normal platelet count or above (5.6 \pm 3.2 vs. $7.6 \pm 4.2 \mathrm{~cm}, p<0.001$; Table 2; see online suppl. Table 2; for all online suppl. material, see www.karger.com/doi/10.1159/000489833). Furthermore, in patients with thrombocytopenia, extrahepatic spread ( 9.5 vs. $20.2 \%, p<0.001)$ and macrovascular invasion (21.2 vs. $31.0 \%, p=0.005$ ) were less common, and these patients had lower BCLC (63.0 vs. 73.4\% BCLC C/D, $p=0.007$ ) and ECOG stages (50.0 vs. $60.1 \%$ ECOG PS $\geq 1, p=0.013$ ).

Patients with an MPV $\geq 11 \mathrm{fL}$ at diagnosis had lower Child-Pugh stage and MELD scores (Table 2). Interestingly, patients with thrombocytopenia and high MPV had significantly more often lower grade tumors (according to Edmondson \& Steiner) compared to patients with other platelet indices (13.9 vs. $22.0 \%$ patients with tumor grade G3/G4; $p=0.033$ ) (see online suppl. Table 2).

\section{Univariate and Multivariate Analysis}

Derivation Cohort

The median OS of all patients was 8.7 months; 527 (84.2\%) patients died during the study period.

Next to established prognostic factors for HCC (Table 3), patients with thrombocytopenia had a significantly longer OS compared to patients with normal platelet counts $\geq 150 \mathrm{~g} / \mathrm{L}$ 
Scheiner et al.: Platelets and HCC

Table 2. Association of platelet count and mean platelet volume with characteristics of tumor and liver disease (derivation cohort)

\begin{tabular}{|c|c|c|c|}
\hline Platelets & $\begin{array}{l}\text { Normal platelet count } \\
(\geq 150 \mathrm{~g} / \mathrm{L})\end{array}$ & $\begin{array}{l}\text { Thrombocytopenia } \\
(<150 \mathrm{~g} / \mathrm{L})\end{array}$ & $p$ value \\
\hline Patients & 248 (39.6\%) & 378 (60.4\%) & \\
\hline Largest tumor, $\mathrm{cm}$ & $7.6 \pm 4.2$ & $5.6 \pm 3.2$ & $<\mathbf{0 . 0 0 1}(t$ test $)$ \\
\hline Extrahepatic spread & $50 / 248(20.2 \%)$ & $36 / 378(9.5 \%)$ & $<0.001\left(\chi^{2}\right)$ \\
\hline Macrovascular invasion & 77/248 (31.0\%) & $80 / 378(21.2 \%)$ & $0.005\left(\chi^{2}\right)$ \\
\hline BCLC stages C+D & $182 / 248(73.4 \%)$ & $238 / 378(63.0 \%)$ & $0.007\left(\chi^{2}\right)$ \\
\hline ECOG PS $\geq 1$ & $149 / 248(60.1 \%)$ & $189 / 378(50.0 \%)$ & $0.013\left(\chi^{2}\right)$ \\
\hline MPV & $\geq 11 \mathrm{fL}$ & $<11 \mathrm{fL}$ & $p$ value \\
\hline Child-Pugh stage, $n$ & $305(100 \%)$ & $321(100 \%)$ & $0.007\left(\chi^{2}\right)$ \\
\hline A & $128(42.0 \%)$ & 106 (33.0\%) & \\
\hline B & $113(37.0 \%)$ & $114(35.5 \%)$ & \\
\hline $\mathrm{C}$ & $64(21.0 \%)$ & $101(31.5 \%)$ & \\
\hline MELD & $11.5(8.9-15.0)$ & $12.3(9.5-16.7)$ & $\mathbf{0 . 0 1 0}$ (Mann-Whitney U) \\
\hline
\end{tabular}

BCLC, Barcelona Clinic Liver Cancer; ECOG PS, Eastern Cooperative Oncology Group performance status; MPV, mean platelet volume; MELD, model for end-stage liver disease.

(median OS [95\% CI], 11.5 [9.3-13.8] vs. 5.5 [3.8-7.1] months; $p=0.001$ ). Since only 6 patients (1\%) showed an MPV below the normal range (7 fL), we decided to split the patients into two groups according to the median MPV $(</ \geq 11 \mathrm{fL})$. Patients with an MPV $\geq 11 \mathrm{fL}$ had a significantly better prognosis when compared to patients with a lower MPV (median OS [95\% CI], 11.7 [9.1-14.2] vs. 6.0 [4.4-7.6] months; $p<0.001$ ). Next, we combined the two variables platelet count and platelet volume into a common index and found that the group of patients with thrombocytopenia $(<150 \mathrm{~g} / \mathrm{L})$ and a high MPV $(\geq 11 \mathrm{fL})$ had a significantly longer OS (median OS [95\% CI], 14.5 [12.4-16.6] months) compared to the three other groups (platelet count low + MPV low, platelet count high + MPV low, platelet count high + MPV high). Thus, we finally grouped the latter three to one group in order to form a dichotomous variable ("low platelets + high MPV" vs. "all other groups"). Again, the newly formed variable was significantly associated with OS (Table 3; Fig. 2).

Importantly, the variable "low platelets + high MPV" remained an independent prognostic factor for OS (HR [95\% CI], 0.80 [0.65-0.98]; $p=0.029$ ) (Table 4) in multivariate analysis adjusting for etiology of liver disease, BCLC and Child-Pugh stage, tumor load, ECOG PS, vascular invasion, and extrahepatic spread as well as first line treatment. The prognostic impact of "low platelets + high MPV" was most pronounced in patients with BCLC stage C (median OS [95\% CI], 11.6 [8.7-14.6] months vs. 5.7 [4.6-6.8] months; $p=0.007$; Fig. 3a) and BCLC stage D (median OS [95\% CI], 5.0 [3.1-6.9] vs. 1.6 [1.3-1.9] months, $p=0.001$; Fig. 3b). No significant differences were found in BCLC stage A and B patients (see online suppl. Table 3).

In order to exclude a potential bias of changes in treatment over time (e.g., approval of sorafenib), Kaplan-Meier analysis was performed in patients diagnosed before and after 2007. In total, 426 patients were diagnosed before and 200 patients in 2007 or later. Again, patients presenting with thrombocytopenia $(<150 \mathrm{~g} / \mathrm{L})$ and a high MPV $(\geq 11 \mathrm{fL})$ at baseline had a significantly longer OS in both subgroups (before 2007, OS: 14.0 [11.2-16.7] vs. 4.3 [3.0-5.6], $p<0.001$; in 2007 or later, OS: 16.3 [10.5-22.2] vs. 10.5 [8.5-12.5], $p=0.012$ ) (see online suppl. Fig. S1). 


\begin{tabular}{l|l}
\hline DOI: $10.1159 / 000489833$ & $\begin{array}{l}\text { C 2018 S. Karger AG, Basel } \\
\text { www.karger.com/lic }\end{array}$ \\
\hline
\end{tabular}

Scheiner et al.: Platelets and HCC

Table 3. Univariate analysis of prognostic factors (derivation cohort)

\begin{tabular}{|c|c|c|c|c|}
\hline & $n$ & Overall s & months & $p$ value \\
\hline & & median & $95 \% \mathrm{CI}$ & \\
\hline Age & & & & \\
\hline$\leq 65$ years & 335 & 6.9 & $4.9-9.0$ & 0.025 \\
\hline$>65$ years & 291 & 10.5 & $8.1-12.9$ & \\
\hline Etiology & & & & \\
\hline Alcohol & 293 & 8.1 & $5.7-10.5$ & 0.011 \\
\hline $\mathrm{HCV}$ & 200 & 11.7 & $8.8-14.6$ & \\
\hline HBV & 42 & 4.3 & $2.6-6.0$ & \\
\hline NASH & 14 & 16.2 & $9.2-23.2$ & \\
\hline Other & 77 & 6.1 & $3.6-8.5$ & \\
\hline Child-Pugh & & & & \\
\hline A & 234 & 15.8 & $12.7-18.9$ & $<0.001$ \\
\hline B & 227 & 9.6 & $6.7-12.5$ & \\
\hline $\mathrm{C}$ & 165 & 2.3 & $1.7-2.9$ & \\
\hline Ascites & & & & \\
\hline No & 292 & 16.2 & $13.2-19.2$ & $<0.001$ \\
\hline Yes & 334 & 4.0 & $3.2-4.8$ & 0.001 \\
\hline Largest tumor & & & & \\
\hline$\leq 5 \mathrm{~cm}$ & 286 & 14.3 & $11.9-16.7$ & $<0.001$ \\
\hline$>5 \mathrm{~cm}$ & 340 & 5.4 & $4.4-6.4$ & \\
\hline ECOG PS & & & & \\
\hline 0 & 288 & 18.8 & $15.7-22.0$ & $<0.001$ \\
\hline$\geq 1$ & 338 & 3.8 & $3.2-4.5$ & \\
\hline Macrovascular invasion & & & & \\
\hline No & 469 & 11.6 & $9.5-13.7$ & $<0.001$ \\
\hline Yes & 157 & 3.8 & $2.3-5.3$ & \\
\hline Tumor extent & & & & \\
\hline Unifocal & 222 & 13.2 & $10.4-16.0$ & $<0.001$ \\
\hline Multifocal & 404 & 7.2 & $5.4-9.0$ & \\
\hline Extrahepatic spread & & & & \\
\hline No & 540 & 11.5 & $9.0-13.1$ & $<0.001$ \\
\hline Yes & 86 & 3.3 & $2.2-4.3$ & \\
\hline BCLC & & & & \\
\hline A & 72 & 39.1 & $15.6-62.5$ & $<0.001$ \\
\hline B & 134 & 20.8 & $17.0-24.7$ & \\
\hline $\mathrm{C}$ & 252 & 6.5 & $5.1-7.9$ & \\
\hline D & 168 & 2.3 & $1.7-2.8$ & \\
\hline First-line therapy & & & & \\
\hline PEI/RFA & 123 & 22.4 & $15.1-29.7$ & $<0.001$ \\
\hline TACE & 165 & 15.5 & $14.0-17.1$ & \\
\hline Sorafenib & 49 & 8.0 & $4.8-11.1$ & \\
\hline BSC & 151 & 1.7 & $1.1-2.3$ & \\
\hline Other & 138 & 5.1 & $3.9-6.4$ & \\
\hline Platelet volume & & & & \\
\hline$<11 \mathrm{fL}$ & 321 & 6.0 & $4.4-7.6$ & $<0.001$ \\
\hline$\geq 11 \mathrm{fL}$ & 305 & 11.7 & $9.1-14.2$ & \\
\hline Platelet count & & & & \\
\hline$<150,000$ cells & 378 & 11.5 & $9.3-13.8$ & 0.001 \\
\hline$\geq 150,000$ cells & 248 & 5.5 & $3.8-7.1$ & \\
\hline Platelet numbers + indices & & & & \\
\hline Platelet low, MPV low & 168 & 6.8 & $3.3-10.2$ & $<0.001$ \\
\hline Platelet low, MPV high & 208 & 14.5 & $12.4-16.6$ & \\
\hline Platelet high, MPV low & 153 & 4.9 & $3.1-6.7$ & \\
\hline Platelet high, MPV high & 97 & 6.0 & $3.2-8.9$ & \\
\hline Low platelets + high MPV & & & & \\
\hline Yes & 208 & 14.5 & $12.4-16.6$ & $<0.001$ \\
\hline No & 418 & 6.0 & $4.5-7.5$ & \\
\hline
\end{tabular}

HCV, hepatitis C virus; HBV, hepatitis B virus; NASH, non-alcoholic steatohepatitis; ECOG PS, Eastern Cooperative Oncology Group performance status; BCLC, Barcelona Clinic Liver Cancer; PEI, percutaneous ethanol injection; RFA, radiofrequency ablation; TACE, transarterial chemoembolization; BSC, best supportive care; MPV, mean platelet volume. 


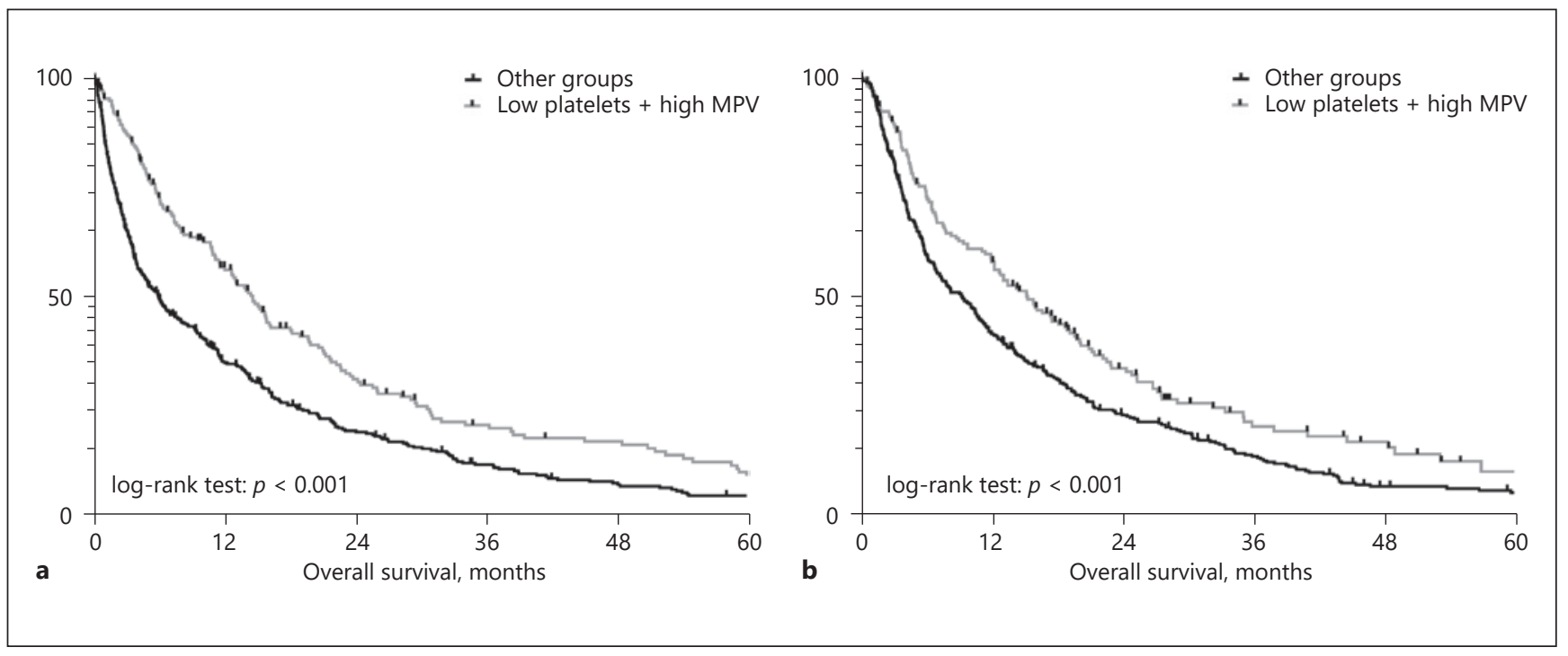

Fig. 2. Comparison of survival between patients with a platelet count $<150 \mathrm{~g} / \mathrm{L}$ and a high mean platelet volume (MPV) vs. patients with other platelet characteristics in the derivation cohort (MPV $\geq 11 \mathrm{fL}$; a) and validation cohort (MPV $\geq 10.6 \mathrm{fL} ; \mathbf{b}$ ).

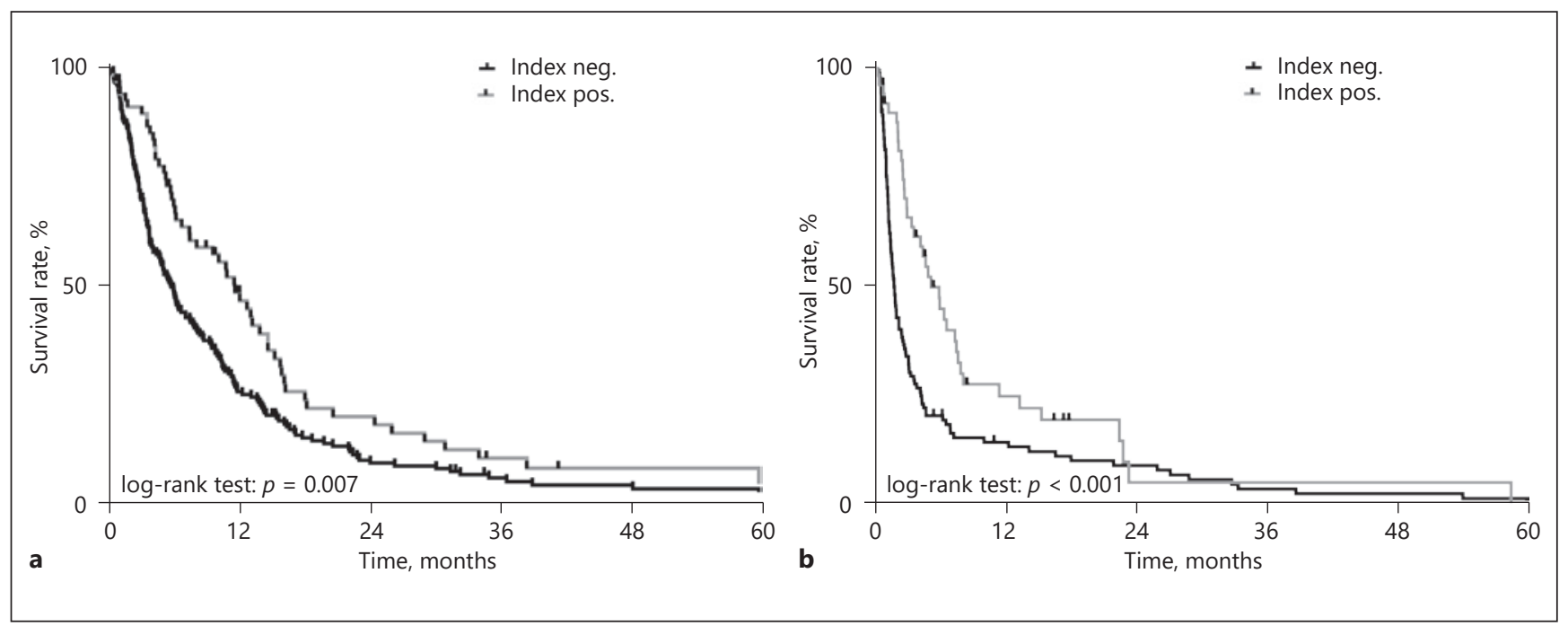

Fig. 3. Comparison of survival between patients with a platelet count $<150 \mathrm{~g} / \mathrm{L}$ and a mean platelet volume (MPV) $\geq 11 \mathrm{fL}$ vs. patients with other platelet characteristics in Barcelona Clinic Liver Cancer (BCLC) stage C (a) and BCLC stage D (b) patients in the derivation cohort.

\section{Validation Cohort}

Similar to the derivation cohort, patients with thrombocytopenia $(<150 \mathrm{~g} / \mathrm{L}, \mathrm{OS}: 12.9[10.7-$ 15.1 ] vs. 7.5 [5.5-9.5]; $p=0.003$ ) and high MPV (OS 12.8 [9.6-16.0] vs. 9.4 [7.3-11.6]; $p=0.001$ ) had a significantly longer OS when compared to patients with other indices (see online suppl. Table 1). Furthermore, the compound variable identified patients with a significantly longer OS (15.3 [11.7-18.9] vs. 9.3 [7.4-11.2]; $p<0.001$ ). In multivariate analysis adjusting for other important prognostic factors, presence of thrombocytopenia and a high MPV was independently associated with a $24 \%$ risk reduction for death (HR 0.76 [0.60-0.95], $p=0.015$ ) (Table 5). 
Table 4. Multivariate analysis of prognostic factors (derivation cohort)

\begin{tabular}{|c|c|c|c|}
\hline & \multicolumn{2}{|c|}{ Overall survival } & \multirow{2}{*}{$\begin{array}{l}p \text { value } \\
\text { (Cox regression) }\end{array}$} \\
\hline & $\mathrm{HR}$ & $95 \% \mathrm{CI}$ & \\
\hline \multicolumn{4}{|l|}{ Etiology } \\
\hline Alcohol & 1 & & \\
\hline $\mathrm{HCV}$ & 0.91 & $0.74-1.12$ & 0.357 \\
\hline $\mathrm{HBV}$ & 1.97 & $1.38-2.82$ & $<0.001$ \\
\hline NASH & 0.95 & $0.50-1.81$ & 0.879 \\
\hline Other & 1.35 & $1.02-1.78$ & 0.037 \\
\hline \multicolumn{4}{|l|}{ Child-Pugh stage } \\
\hline A & 1 & & \\
\hline B & 1.24 & $0.97-1.57$ & 0.084 \\
\hline $\mathrm{C}$ & 1.31 & $0.40-4.32$ & 0.661 \\
\hline \multicolumn{4}{|l|}{ Ascites } \\
\hline No & 1 & & \\
\hline Yes & 1.57 & $1.26-1.95$ & $<0.001$ \\
\hline \multicolumn{4}{|l|}{ BCLC stage } \\
\hline A & 1 & & \\
\hline B & 1.09 & $0.73-1.63$ & 0.661 \\
\hline $\mathrm{C}$ & 1.05 & $0.68-1.61$ & 0.838 \\
\hline D & 1.61 & $0.46-5.68$ & 0.462 \\
\hline \multicolumn{4}{|l|}{ Largest tumor } \\
\hline$\leq 5 \mathrm{~cm}$ & 1 & & \\
\hline$>5 \mathrm{~cm}$ & 1.39 & $1.14-1.69$ & 0.001 \\
\hline \multicolumn{4}{|l|}{ Tumor extent } \\
\hline Unifocal & 1 & & \\
\hline Multifocal & 1.50 & $1.22-1.84$ & $<0.001$ \\
\hline \multicolumn{4}{|l|}{ ECOG PS } \\
\hline 0 & 1 & & \\
\hline$\geq 1$ & 1.56 & $1.17-2.09$ & 0.003 \\
\hline \multicolumn{4}{|c|}{ Macrovascular invasion } \\
\hline No & 1 & & \\
\hline Yes & 1.72 & $1.35-2.20$ & $<0.001$ \\
\hline \multicolumn{4}{|l|}{ Extrahepatic spread } \\
\hline No & 1 & & \\
\hline Yes & 1.63 & $1.24-2.13$ & $<0.001$ \\
\hline \multicolumn{4}{|l|}{ First-line treatment } \\
\hline PEI/RFA/MWA & 1 & & \\
\hline $\mathrm{TA}(\mathrm{C}) \mathrm{E}$ & 1.40 & $1.05-1.86$ & 0.021 \\
\hline Sorafenib & 1.22 & $0.79-1.90$ & 0.371 \\
\hline Other & 2.00 & $1.49-2.68$ & $<0.001$ \\
\hline $\mathrm{BSC}$ & 3.65 & $2.65-4.94$ & $<0.001$ \\
\hline \multicolumn{4}{|c|}{ Low platelets + high MPV } \\
\hline No & 1 & & \\
\hline Yes & 0.80 & $0.65-0.98$ & 0.029 \\
\hline
\end{tabular}

HCV, hepatitis C virus; HBV, hepatitis B virus; NASH, non-alcoholic steatohepatitis; BCLC, Barcelona Clinic Liver Cancer; ECOG PS, Eastern Cooperative Oncology Group performance status; PEI, percutaneous ethanol injection; RFA, radiofrequency ablation; MWA, microwave ablation; TA(C)E, transarterial (chemo)embolization; BSC, best supportive care; MPV, mean platelet volume. 


\section{Liver Cancer}

\begin{tabular}{|c|c|}
\hline \multicolumn{2}{|c|}{ Liver Cancer 2019;8:203-217 } \\
\hline DOI: 10.1159/000489833 & $\begin{array}{l}\text { (c) } 2018 \text { S. Karger AG, Basel } \\
\text { www.karger.com/lic }\end{array}$ \\
\hline
\end{tabular}

Scheiner et al.: Platelets and HCC

Table 5. Multivariate analysis of prognostic factors (validation cohort)

\begin{tabular}{|c|c|c|c|}
\hline & \multicolumn{2}{|c|}{ Overall survival } & \multirow{2}{*}{$\begin{array}{l}p \text { value } \\
\text { (Cox regression) }\end{array}$} \\
\hline & HR & $95 \% \mathrm{CI}$ & \\
\hline \multicolumn{4}{|l|}{ Child-Pugh score } \\
\hline A & 1 & & \\
\hline B & 1.58 & $1.23-2.03$ & $<0.001$ \\
\hline $\mathrm{C}$ & 1.65 & $0.48-5.69$ & 0.425 \\
\hline \multicolumn{4}{|l|}{ Ascites } \\
\hline No & 1 & & \\
\hline Yes & 1.41 & $1.11-1.81$ & 0.005 \\
\hline \multicolumn{4}{|l|}{ BCLC stage } \\
\hline A & 1 & & \\
\hline B & 0.88 & $0.59-1.31$ & 0.517 \\
\hline $\mathrm{C}$ & 0.80 & $0.48-1.33$ & 0.392 \\
\hline $\mathrm{D}$ & 1.11 & $0.32-4.03$ & 0.836 \\
\hline \multicolumn{4}{|l|}{ Largest tumor } \\
\hline$\leq 5 \mathrm{~cm}$ & 1 & & \\
\hline$>5 \mathrm{~cm}$ & 1.12 & $0.90-1.40$ & 0.317 \\
\hline \multicolumn{4}{|l|}{ Tumor extent } \\
\hline Unifocal & 1 & & \\
\hline Multifocal & 1.23 & $0.95-1.60$ & 0.123 \\
\hline \multicolumn{4}{|l|}{ ECOG PS } \\
\hline 0 & 1 & & \\
\hline$\geq 1$ & 1.16 & $0.80-1.67$ & 0.442 \\
\hline \multicolumn{4}{|c|}{ Macrovascular invasion } \\
\hline No & 1 & & \\
\hline Yes & 1.44 & $1.06-1.95$ & 0.019 \\
\hline \multicolumn{4}{|l|}{ Extrahepatic spread } \\
\hline No & 1 & & \\
\hline Yes & 1.81 & $1.15-2.85$ & 0.010 \\
\hline \multicolumn{4}{|l|}{ First-line treatment } \\
\hline PEI/RFA/MWA & 1 & & \\
\hline TACE & 1.28 & $0.91-1.79$ & 0.156 \\
\hline Sorafenib & 1.37 & $0.33-5.80$ & 0.666 \\
\hline BSC & 4.74 & $3.30-6.80$ & $<0.001$ \\
\hline Other & 1.18 & $0.75-1.85$ & 0.473 \\
\hline \multicolumn{4}{|c|}{ Low platelets + high MPV } \\
\hline No & 1 & & \\
\hline Yes & 0.76 & $0.60-0.95$ & 0.015 \\
\hline
\end{tabular}

BCLC, Barcelona Clinic Liver Cancer; ECOG PS, Eastern Cooperative Oncology Group performance status; PEI, percutaneous ethanol injection; RFA, radiofrequency ablation; MWA, microwave ablation; TACE, transarterial chemoembolization; BSC, best supportive care; MPV, mean platelet volume.

\section{Discussion}

Thrombocytopenia is a common finding in patients with liver cirrhosis and is associated with increased morbidity and mortality [32]. Furthermore, it was thought to be a risk factor for the development of HCC [25]. However, it is unclear if thrombocytopenia per se is a risk factor for HCC development or just a phenomenon of more advanced liver disease, associated with an increased HCC incidence. Recently, platelets received considerable attention in tumor biology [12, 33-35]. Several studies showed that thrombocytosis, not thrombocytopenia, is associated with more frequent distant metastasis in various cancer entities [19, 


\section{Liver
Cancer}

\begin{tabular}{|c|c|}
\hline \multicolumn{2}{|l|}{ Liver Cancer 2019;8:203-217 } \\
\hline DOI: 10.1159/000489833 & $\begin{array}{l}\text { (c) } 2018 \text { S. Karger AG, Basel } \\
\text { www.karger.com/lic }\end{array}$ \\
\hline
\end{tabular}

Scheiner et al.: Platelets and HCC

$33,36,37]$. However, the cellular and molecular mechanisms remain unclear; it might well be that thrombocytosis "just" reflects cancer-driven systemic inflammation. In cirrhotic patients with a high prevalence of hepatic dysfunction, portal hypertension, and splenomegaly/hypersplenism, the pathophysiology of thrombocytopenia is more complex per se $[38,39]$.

In our large cohort of 626 cirrhotic HCC patients not eligible for surgery, thrombocytopenia was associated with smaller tumors and a two times longer OS when compared to patients with a platelet count within the normal range or above. This is in line with other studies showing an association of thrombocytopenia and smaller tumor size when compared to patients with higher platelet counts [40-42]. Pathophysiologically, it was shown that platelets play a proinflammatory role in the course of chronic liver disease. Iannacone et al. [43] demonstrated that activated platelets cause an intrahepatic cytotoxic $\mathrm{T}$ lymphocyte accumulation and organ damage in a mouse model of acute viral hepatitis. Furthermore, platelets release serotonin, which on the one hand has an important role in liver regeneration [44], but on the other hand also exerts direct tumor-promoting effects on HCC cells. A preclinical study found that serotonin is involved in growth of HCC by activating downstream targets of the mammalian target of rapamycin [45].

Next, we found that higher MPV was also associated with a significantly longer OS. While previous studies in non-cancer patients suggested that larger thrombocytes are functionally more active and elevated MPV was associated with various thrombotic events and a worse outcome [46, 47], a higher MPV was associated with a significantly increased survival in patients with various solid tumors [29]. In this context, low MPV may reflect degranulated "exhausted" platelets that have already secreted their potentially tumor growth-promoting cytokines, and thus are associated with a worse outcome in cancer patients [48, 49].

Notably, in chronic hepatitis B and C patients, elevated MPV levels were suggested as a marker of more advanced liver disease [50,51]. Another study found an increase in MPV during ascitic fluid infection [52]. However, a recent examination in patients with established cirrhosis could not find an association of MPV levels and severity of cirrhosis or prognosis [53].

While thrombocytopenia in cirrhosis has several reasons, low MPV in this setting is most likely the result of reduced thrombopoietin (TPO) production and cirrhotic bone marrow suppression [54]. Thus, we believe that higher MPV could also reflect a better remaining liver function in terms of TPO production and bone marrow function.

Therefore, mechanistically, our findings may reflect less platelet-mediated tumor growthpromoting effects (low platelets, higher MPV) and a better remaining liver function (higher MPV). Accordingly, in our cohort, thrombocytopenia was strongly associated with less aggressive tumor characteristics (such as smaller tumors, less extrahepatic metastasis and vascular invasion), and higher MPV was associated with better liver function parameters (such as lower Child-Pugh stage and a lower MELD). This hypothesis is further supported by the fact that the impact of our combined variable was greatest in patients with more advanced HCC stages and more severe liver dysfunction (BCLC C and D patients) as well as the lower histological tumor grades in these patients. The fact that thrombocytopenia is indeed associated with improved outcomes in most advanced stages is even more interesting when considering that the level of thrombocytopenia also reflects severity of portal hypertension, a major driver of complications in patients with cirrhosis [55]. Furthermore, it remains to be established if tyrosine kinase inhibitors (such as sorafenib), which also inhibit plateletderived growth factor signalling [56,57], interfere with the effects of thrombocytopenia in HCC. However, a subgroup analysis in patients diagnosed before and after the approval of sorafenib showed that even though OS improved in the whole cohort, patients presenting with thrombocytopenia and higher MPV still had a significantly better survival. 


\section{Liver Cancer}

This study underlines the important role of platelets in the natural course of HCC. Up to now, studies reported that patients with thrombocytosis had a reduced OS per se. However, we could show that not only the overall platelet count was determining survival, but also and especially the degranulation status of these platelets is important. This theory is supported by the fact that thrombocytosis alone was only borderline significant in multivariate analysis (data not shown).

Furthermore, this study suggests a potential role for antiplatelet therapy. In fact, a prospective study analyzing over 300,000 patients showed that patients receiving acetylsalicylic acid had a significantly lower risk of developing HCC [58]. Antiplatelet therapy could also prevent HCC in a mouse model of chronic hepatitis B [59].

Even though routine screening programs in patients with chronic liver disease often allow earlier identification of patients with HCC, the number of patients diagnosed in advanced tumor stages is still high in Western countries $[60,61]$. For these patients, sorafenib was the only approved treatment for almost a decade until the recent approval of the multi-tyrosine kinase inhibitor regorafenib as second-line therapy [62]. Other tyrosine kinase inhibitors, namely lenvatinib and cabozantinib $[63,64]$, have already demonstrated efficacy in phase III trials and will certainly help to improve the outcome of patients with advanced-stage HCC. Additionally, immunotherapy as a new treatment strategy is becoming more and more available, and driven by the promising data of nivolumab (CheckMate 040 study) [65], immunotherapy is increasingly used off-label as last-line option in patients otherwise admitted to best supportive care [66].

The main limitation of this study is the retrospective nature with all its possible shortcomings (e.g., potential impact of unmeasured confounders). Due to the retrospective design, our results have a hypothesis-generating character. Importantly, we were able to reproduce our results in a large external independent validation cohort, which further strengthens the validity of our results. However, randomized controlled trials are needed to confirm our findings prospectively. Additionally, as thrombocytopenia reflects more advanced liver disease, patients with thrombocytopenia might generally be screened more rigorously for HCC. To minimize this potential bias, we excluded patients without liver cirrhosis, who do not frequently undergo HCC surveillance. However, to the best of our knowledge, this is the first study using an index of thrombocytopenia and MPV as a compound variable in two large cohorts of HCC patients. These simple parameters allow an estimation of a favorable prognosis in cirrhotic HCC patients.

In summary, we found that thrombocytopenia and higher MPV were associated with improved survival in cirrhotic patients with unresectable HCC, independent of other established prognostic tumor- and liver-related variables. These findings may prompt further clinical research on additive antiplatelet therapy in the prevention and management of HCC.

\section{Disclosure Statement}

B.S. received travel support from Gilead; M.M.K. received speaker and consulting fees from Shire, Roche, and BMS; S.P. has nothing to declare, F.H. and S.B. received travel support from Bayer; N.R.-U. received travel support or honoraria from Roche and Bayer HealthCare; M.P.R. received grant support and honoraria from Bayer HealthCare and BMS, and served as a consultant for Bayer HealthCare, BMS, Lilly, ONXEO, and Eisai; T.R. received travel support from Gilead, Roche, MSD, and Gore, grant support from Gilead, Abbvie, Philips, Boehringer Ingelheim, Phenex Pharmaceuticals, and Gore, and served as a consultant for MSD, Gilead, Abbvie, and Boehringer Ingelheim; C.M. has nothing to declare; M.T. received grants from MSD, honoraria for consulting from AbbVie, Gilead, Janssen, and MSD, payments for lectures from Gilead, MSD, and Roche, as well as travel support from Gilead; A.V. received speaker and consulting fees from Bayer, Lilly, Roche, BMS and MSD; W.S. received speaker and consulting fees and research grants from Bayer Schering Pharma; M.P. is advisory board member of Bayer, BMS, and Eisai, and received travel support from Bayer and speaking fees from Bayer and BMS. He is also an investigator for Bayer, BMS, and Lilly. 
Scheiner et al.: Platelets and HCC

\section{Funding Sources}

None.

\section{Author Contributions}

Concept of the study (B.S., W.S., M.P.), extraction of data (B.S., M.M.K., S.P., S.B., A.V., M.P.), drafting of the manuscript (B.S., S.P., W.S., M.P.), writing of the manuscript (B.S., M.P.), revision for important intellectual content (all authors). B.S. acts as the guarantor of the article, and all authors approved the final version of the manuscript.

\section{References}

1 European Association for the Study of the Liver, European Organisation for Research and Treatment of Cancer. EASL-EORTC clinical practice guidelines: management of hepatocellular carcinoma. J Hepatol 2012;56:908943.

2 Hucke F, Sieghart W, Schoniger-Hekele M, Peck-Radosavljevic M, Muller C: Clinical characteristics of patients with hepatocellular carcinoma in Austria - is there a need for a structured screening program? Wien Klin Wochenschr 2011;123:542-551.

3 Pinter M, Trauner M, Peck-Radosavljevic M, Sieghart W: Cancer and liver cirrhosis: implications on prognosis and management. ESMO Open 2016;1:e000042.

4 Torre LA, Bray F, Siegel RL, Ferlay J, Lortet-Tieulent J, Jemal A: Global cancer statistics, 2012. CA Cancer J Clin 2015;65:87-108.

5 Llovet JM, Bruix J: Molecular targeted therapies in hepatocellular carcinoma. Hepatology 2008;48:1312-1327.

6 Yeh CN, Chen MF, Lee WC, Jeng LB: Prognostic factors of hepatic resection for hepatocellular carcinoma with cirrhosis: univariate and multivariate analysis. J Surg Oncol 2002;81:195-202.

7 Kudo M: Signaling pathway and molecular-targeted therapy for hepatocellular carcinoma. Dig Dis 2011;29: 289-302.

8 Pinter M, Sieghart W, Hucke F, Graziadei I, Vogel W, Maieron A, et al: Prognostic factors in patients with advanced hepatocellular carcinoma treated with sorafenib. Aliment Pharmacol Ther 2011;34:949-959.

9 Wang Y, Attar BM, Fuentes HE, Jaiswal P, Tafur AJ: Evaluation of the prognostic value of platelet to lymphocyte ratio in patients with hepatocellular carcinoma. J Gastrointest Oncol 2017;8:1065-1071.

10 Ozaki Y, Tamura S, Suzuki-Inoue K: New horizon in platelet function: with special reference to a recently-found molecule, CLEC-2. Thromb J 2016;14(suppl 1):27.

11 Starlinger P, Haegele S, Offensperger F, Oehlberger L, Pereyra D, Kral JB, et al: The profile of platelet alphagranule released molecules affects postoperative liver regeneration. Hepatology 2016;63:1675-1688.

12 Karpatkin S, Pearlstein E, Ambrogio C, Coller BS: Role of adhesive proteins in platelet tumor interaction in vitro and metastasis formation in vivo. J Clin Invest 1988;81:1012-1019.

13 McFadyen JD, Kaplan ZS: Platelets are not just for clots. Transfus Med Rev 2015;29:110-119.

14 Amano H, Ito Y, Ogawa F, Eshima K, Suzuki T, Oba K, et al: Angiotensin II type 1A receptor signaling facilitates tumor metastasis formation through P-selectin-mediated interaction of tumor cells with platelets and endothelial cells. Am J Pathol 2013;182:553-564.

15 Cheng J, Zeng Z, Ye Q, Zhang Y, Yan R, Liang C, et al: The association of pretreatment thrombocytosis with prognosis and clinicopathological significance in cervical cancer: a systematic review and meta-analysis. Oncotarget 2017;8:24327-24336.

16 Choi JY, Ko YH, Song PH: Clinical significance of preoperative thrombocytosis in patients who underwent radical nephrectomy for nonmetastatic renal cell carcinoma. Investig Clin Urol 2016;57:324-329.

17 Kizer NT, Hatem H, Nugent EK, Zhou G, Moore K, Heller P, et al: Chemotherapy response rates among patients with endometrial cancer who have elevated serum platelets. Int J Gynecol Cancer 2015;25:1015-1022.

18 Yang HJ, Jiang JH, Liu QA, Zhou CM, Du YF, Wu T, et al: Preoperative platelet-to-lymphocyte ratio is a valuable prognostic biomarker in patients with hepatocellular carcinoma undergoing curative liver resection. Tumour Biol 2017;39:1010428317707375.

19 Lee CH, Lin YJ, Lin CC, Yen CL, Shen CH, Chang CJ, et al: Pretreatment platelet count early predicts extrahepatic metastasis of human hepatoma. Liver Int 2015;35:2327-2336.

20 Xue TC, Ge NL, Xu X, Le F, Zhang BH, Wang YH: High platelet counts increase metastatic risk in huge hepatocellular carcinoma undergoing transarterial chemoembolization. Hepatol Res 2016;46:1028-1036.

21 Han S, Lee S, Yang JD, Leise MD, Ahn JH, Kim S, et al: Risk of posttransplant hepatocellular carcinoma recurrence is greater in recipients with higher platelet counts in living donor liver transplantation. Liver Transpl 2018;24:44-55.

22 Rothwell PM, Wilson M, Price JF, Belch JF, Meade TW, Mehta Z: Effect of daily aspirin on risk of cancer metastasis: a study of incident cancers during randomised controlled trials. Lancet 2012;379:1591-1601. 
23 Rothwell PM, Price JF, Fowkes FG, Zanchetti A, Roncaglioni MC, Tognoni G, et al: Short-term effects of daily aspirin on cancer incidence, mortality, and non-vascular death: analysis of the time course of risks and benefits in 51 randomised controlled trials. Lancet 2012;379:1602-1612.

24 Lok AS, Seeff LB, Morgan TR, di Bisceglie AM, Sterling RK, Curto TM, et al: Incidence of hepatocellular carcinoma and associated risk factors in hepatitis C-related advanced liver disease. Gastroenterology 2009;136:138148.

25 Everson GT, Shiffman ML, Hoefs JC, Morgan TR, Sterling RK, Wagner DA, et al: Quantitative liver function tests improve the prediction of clinical outcomes in chronic hepatitis C: results from the Hepatitis C Antiviral Longterm Treatment against Cirrhosis Trial. Hepatology 2012;55:1019-1029.

26 Zhuang Q, Xiang L, Xu H, Fang F, Xing C, Liang B, et al: The independent association of mean platelet volume with overall survival in multiple myeloma. Oncotarget 2016; 7:62640-62646.

27 Yun ZY, Zhang X, Liu YS, Liu T, Liu ZP, Wang RT, et al: Lower mean platelet volume predicts poor prognosis in renal cell carcinoma. Sci Rep 2017;7:6700.

28 Rupa-Matysek J, Gil L, Kroll-Balcerzak R, Baranska M, Komarnicki M: Mean platelet volume as a predictive marker for venous thromboembolism and mortality in patients treated for diffuse large B-cell lymphoma. Hematol Oncol 2017;35:456-464.

29 Riedl J, Kaider A, Reitter EM, Marosi C, Jager U, Schwarzinger I, et al: Association of mean platelet volume with risk of venous thromboembolism and mortality in patients with cancer. Results from the Vienna Cancer and Thrombosis Study (CATS). Thromb Haemost 2014;111:670-678.

30 Zhang Z, Zhang Y, Wang W, Hua Y, Liu L, Shen S, et al: Thrombocytopenia and the outcomes of hepatectomy for hepatocellular carcinoma: a meta-analysis. J Surg Res 2017;210:99-107.

31 Reiberger T, Puspok A, Schoder M, Baumann-Durchschein F, Bucsics T, Datz C, et al: Austrian consensus guidelines on the management and treatment of portal hypertension (Billroth III). Wien Klin Wochenschr 2017; 129(suppl 3):135-158.

32 Realdi G, Fattovich G, Hadziyannis S, Schalm SW, Almasio P, Sanchez-Tapias J, et al: Survival and prognostic factors in 366 patients with compensated cirrhosis type B: a multicenter study. The Investigators of the European Concerted Action on Viral Hepatitis (EUROHEP). J Hepatol 1994;21:656-666.

33 Stanger BZ, Kahn ML: Platelets and tumor cells: a new form of border control. Cancer Cell 2013;24:9-11.

34 Philippe C, Philippe B, Fouqueray B, Perez J, Lebret M, Baud L: Protection from tumor necrosis factor-mediated cytolysis by platelets. Am J Pathol 1993;143:1713-1723.

35 Bambace NM, Holmes CE: The platelet contribution to cancer progression. J Thromb Haemost 2011;9:237249.

36 Carr BI, Cavallini A, D’Alessandro R, Refolo MG, Lippolis C, Mazzocca A, et al: Platelet extracts induce growth, migration and invasion in human hepatocellular carcinoma in vitro. BMC Cancer 2014;14:43.

37 Cho MS, Bottsford-Miller J, Vasquez HG, Stone R, Zand B, Kroll MH, et al: Platelets increase the proliferation of ovarian cancer cells. Blood 2012;120:4869-4872.

38 Peck-Radosavljevic M: Thrombocytopenia in chronic liver disease. Liver Int 2017;37:778-793.

39 Peck-Radosavljevic M, Zacherl J, Meng YG, Pidlich J, Lipinski E, Langle F, et al: Is inadequate thrombopoietin production a major cause of thrombocytopenia in cirrhosis of the liver? J Hepatol 1997;27:127-131.

40 Carr BI, Guerra V, Pancoska P: Thrombocytopenia in relation to tumor size in patients with hepatocellular carcinoma. Oncology 2012;83:339-345.

41 Carr BI, Guerra V: Thrombocytosis and hepatocellular carcinoma. Dig Dis Sci 2013;58:1790-1796.

42 Pang Q, Qu K, Zhang JY, Song SD, Liu SS, Tai MH, et al: The prognostic value of platelet count in patients with hepatocellular carcinoma: a systematic review and meta-analysis. Medicine (Baltimore) 2015;94:e1431.

43 Iannacone M, Sitia G, Isogawa M, Marchese P, Castro MG, Lowenstein PR, et al: Platelets mediate cytotoxic T lymphocyte-induced liver damage. Nat Med 2005;11:1167-1169.

44 Lesurtel M, Clavien PA: Serotonin: a key molecule in acute and chronic liver injury! Clin Res Hepatol Gastroenterol 2012;36:319-322.

45 Soll C, Jang JH, Riener MO, Moritz W, Wild PJ, Graf R, et al: Serotonin promotes tumor growth in human hepatocellular cancer. Hepatology 2010;51:1244-1254.

46 Slavka G, Perkmann T, Haslacher H, Greisenegger S, Marsik C, Wagner OF, et al: Mean platelet volume may represent a predictive parameter for overall vascular mortality and ischemic heart disease. Arterioscler Thromb Vasc Biol 2011;31:1215-1218.

47 Greisenegger S, Endler G, Hsieh K, Tentschert S, Mannhalter C, Lalouschek W: Is elevated mean platelet volume associated with a worse outcome in patients with acute ischemic cerebrovascular events? Stroke 2004;35: 1688-1691.

48 Riedl J, Kaider A, Marosi C, Prager GW, Eichelberger B, Assinger A, et al: Decreased platelet reactivity in patients with cancer is associated with high risk of venous thromboembolism and poor prognosis. Thromb Haemost 2017;117:90-98.

49 Boneu B, Bugat R, Boneu A, Eche N, Sie P, Combes PF: Exhausted platelets in patients with malignant solid tumors without evidence of active consumption coagulopathy. Eur J Cancer Clin Oncol 1984;20:899-903.

50 Eminler AT, Uslan MI, Ayyildiz T, Irak K, Kiyici M, Gurel S, et al: Mean platelet volume is an important predictor of hepatitis C but not hepatitis B liver damage. J Res Med Sci 2015;20:865-870.

51 Ekiz F, Yuksel O, Kocak E, Yilmaz B, Altinbas A, Coban S, et al: Mean platelet volume as a fibrosis marker in patients with chronic hepatitis B. J Clin Lab Anal 2011;25:162-165. 
52 Suvak B, Torun S, Yildiz H, Sayilir A, Yesil Y, Tas A, et al: Mean platelet volume is a useful indicator of systemic inflammation in cirrhotic patients with ascitic fluid infection. Ann Hepatol 2013;12:294-300.

53 Giannini EG, Moscatelli A, Brunacci M, Zentilin P, Savarino V: Prognostic role of mean platelet volume in patients with cirrhosis. Dig Liver Dis 2016;48:409-413.

54 Balduini CL, Noris P, Spedini P, Belletti S, Zambelli A, Da Prada GA: Relationship between size and thiazole orange fluorescence of platelets in patients undergoing high-dose chemotherapy. Br J Haematol 1999;106: 202-207.

55 de Franchis R, Baveno VIF: Expanding consensus in portal hypertension: report of the Baveno VI Consensus Workshop: stratifying risk and individualizing care for portal hypertension. J Hepatol 2015;63:743-752.

56 Pinter M, Sieghart W, Reiberger T, Rohr-Udilova N, Ferlitsch A, Peck-Radosavljevic M: The effects of sorafenib on the portal hypertensive syndrome in patients with liver cirrhosis and hepatocellular carcinoma - a pilot study. Aliment Pharmacol Ther 2012;35:83-91.

57 Reiberger T, Angermayr B, Schwabl P, Rohr-Udilova N, Mitterhauser M, Gangl A, et al: Sorafenib attenuates the portal hypertensive syndrome in partial portal vein ligated rats. J Hepatol 2009;51:865-873.

58 Sahasrabuddhe VV, Gunja MZ, Graubard BI, Trabert B, Schwartz LM, Park Y, et al: Nonsteroidal anti-inflammatory drug use, chronic liver disease, and hepatocellular carcinoma. J Natl Cancer Inst 2012;104:1808-1814.

59 Sitia G, Aiolfi R, Di Lucia P, Mainetti M, Fiocchi A, Mingozzi F, et al: Antiplatelet therapy prevents hepatocellular carcinoma and improves survival in a mouse model of chronic hepatitis B. Proc Natl Acad Sci USA 2012; 109:E2165-E2172.

60 Park JW, Chen M, Colombo M, Roberts LR, Schwartz M, Chen PJ, et al: Global patterns of hepatocellular carcinoma management from diagnosis to death: the BRIDGE Study. Liver Int 2015;35:2155-2166.

61 Adhoute X, Penaranda G, Raoul JL, Edeline J, Blanc JF, Pol B, et al: Barcelona clinic liver cancer nomogram and others staging/scoring systems in a French hepatocellular carcinoma cohort. World J Gastroenterol 2017;23: 2545-2555.

62 Bruix J, Qin S, Merle P, Granito A, Huang YH, Bodoky G, et al: Regorafenib for patients with hepatocellular carcinoma who progressed on sorafenib treatment (RESORCE): a randomised, double-blind, placebocontrolled, phase 3 trial. Lancet 2017;389:56-66.

63 Kudo M, Finn RS, Qin S, Han KH, Ikeda K, Piscaglia F, et al: Lenvatinib versus sorafenib in first-line treatment of patients with unresectable hepatocellular carcinoma: a randomised phase 3 non-inferiority trial. Lancet 2018;391:1163-1173.

64 Abou-Alfa GK, Meyer T, Cheng A-L, El-Khoueiry AB, Rimassa L, Ryoo B-Y, et al: Cabozantinib (C) versus placebo (P) in patients (pts) with advanced hepatocellular carcinoma (HCC) who have received prior sorafenib: results from the randomized phase III CELESTIAL trial. J Clin Oncol 2018;36(suppl):207-207.

65 El-Khoueiry AB, Sangro B, Yau T, Crocenzi TS, Kudo M, Hsu C, et al: Nivolumab in patients with advanced hepatocellular carcinoma (CheckMate 040): an open-label, non-comparative, phase $1 / 2$ dose escalation and expansion trial. Lancet 2017;389:2492-2502.

66 Feng D, Hui X, Shi-Chun L, Yan-Hua B, Li C, Xiao-Hui L, et al: Initial experience of anti-PD1 therapy with nivolumab in advanced hepatocellular carcinoma. Oncotarget 2017;8:96649-96655. 